\title{
The frequency of cytomegalovirus non-ELR UL146 genotypes in neonates with congenital CMV disease is comparable to strains in the background population
}

Christian Berg ${ }^{1,2,3^{*}}$, Mette M. Rosenkilde ${ }^{3}$, Thomas Benfield ${ }^{2}$, Lene Nielsen ${ }^{4}$, Thomas Sundelin ${ }^{4}$ and Hans R. Lüttichau ${ }^{1,3^{*}}$ (D)

\begin{abstract}
Background: Congenital cytomegalovirus disease (CCMV) is common and can be fatal or cause severe sequelae. Circulating strains of cytomegalovirus carry a high number of variable or disrupted genes. One of these is UL146, a highly diverse gene with 14 distinct genotypes encoding a CXC-chemokine involved in viral dissemination. UL146 genotypes 5 and 6 lack the conserved ELR motif, potentially affecting strain virulence. Here, we investigate whether UL146 genotypes 5 and 6 were associated with congenital CMV infection.

Methods: Viral DNA was extracted and UL146 sequenced from 116 neonatal dried blood spots (DBS) stored in the Danish National Biobank since 1982 and linked to registered cCMV cases through a personal identifier. These sequences were compared to UL146 control sequences obtained from CMV DNA extracted from 83 urine samples from children with suspected bacterial urinary tract infections.

Results: Three non-ELR UL146 genotypes (5 and 6) were observed among the cases (2.6\%) and two were observed among the controls $(2.4 \% ; P>0.99)$. Additionally, no significant association with cCMV was found for the other 12 genotypes in a post-hoc analysis, although genotype 8 showed a tendency to be more frequent among cases with 12 observations against three $(P=0.10)$. All fourteen genotypes were found to have little intra-genotype variation. Viral load, gender, and sample age were not found to be associated with any particular UL146 genotype.
\end{abstract}

Conclusions: No particular UL146 genotype was associated with CCMV in this nationwide retrospective casecontrol study. Associations between CMV disease and disrupted or polymorph CMV genes among immunosuppressed people living with HIV/AIDS and transplant recipients should be investigated in future studies.

Keywords: UL146, vCXCL1, ELR, DBS, CCMV, Cytomegalovirus, Genotyping

\footnotetext{
*Correspondence: Christian.Berg@regionh.dk;

Hans.Rudolf.von.Luttichau@regionh.dk

'Infectious Diseases Unit, Department of Medicine, Copenhagen University Hospital, Herlev Gentofte, DK-2730 Herlev, Denmark

Full list of author information is available at the end of the article
}

C C The Author(s). 2021 Open Access This article is licensed under a Creative Commons Attribution 4.0 International License, which permits use, sharing, adaptation, distribution and reproduction in any medium or format, as long as you give appropriate credit to the original author(s) and the source, provide a link to the Creative Commons licence, and indicate if changes were made. The images or other third party material in this article are included in the article's Creative Commons licence, unless indicated otherwise in a credit line to the material. If material is not included in the article's Creative Commons licence and your intended use is not permitted by statutory regulation or exceeds the permitted use, you will need to obtain permission directly from the copyright holder. To view a copy of this licence, visit http://creativecommons.org/licenses/by/4.0/. The Creative Commons Public Domain Dedication waiver (http://creativecommons.org/publicdomain/zero/1.0/) applies to the data made available in this article, unless otherwise stated in a credit line to the data. 


\section{Background}

Cytomegalovirus (CMV) is a highly prevalent herpesvirus [1] that is commonly transmitted during early childhood [2-4]. Congenital CMV infection (cCMV), the result of mother-to-fetus transmission, is the most common congenital infection in developed countries with an estimated incidence of $\sim 0.5 \%$ of live births $[5,6]$. Ten percent of infected neonates are symptomatic at birth while $15 \%$ show sequelae at later stages of their childhood $[5,6]$. The symptoms include neurological developmental disorders such as nonhereditary sensorineural hearing loss (SNHL), vision loss, cerebral palsy, intellectual disability, and severe cCMV can lead to pregnancy loss, thus representing a substantial health burden [7].

Cytomegalovirus carries a genome of approximately $235 \mathrm{~kb}$ double-stranded DNA that encodes numerous genes used in dissemination of infection, immune evasion, and establishment of latent infection. A very high degree of genetic diversity caused by disrupted and highly variable genes has been observed between wild type strains $[8,9]$-an unusual observation for DNA viruses-but its effect on the pathogenicity and virulence of individual CMV strains remains to be determined. One of the most diverse genes in the CMV genome is UL146 [8, 9], encoding a viral chemotactic cytokine (chemokine), vCXCL1, which recruits neutrophils to sites of infection through activation of the chemokine receptors CXCR1 and CXCR2 $[10,11]$. The first indication that UL146 is a possible virulence gene, and thereby required for $\mathrm{CMV}$ infection of the human host, came from the observation that the Toledo wild type strain contained a $15 \mathrm{~kb}$ DNA segment containing the UL146 ORF among 22 ORFs not present in laboratory HCMV strains [12]. This indication was recently supported by the finding that recombinant MCMV expressing the UL146 gene enhanced MCMV dissemination kinetics in a mouse [13]. Previous studies have identified 14 distinct UL146 genotypes (GTs) [14] which have shown differences in receptor binding affinity, signaling efficacy, and chemotactic properties [15]. When identifying the UL146 gene product from the Toledo strain (genotype 1) as a CXCR1 and CXCR2 agonist [10], we previously noticed that the sequences of two other genotypes-genotypes 5 and 6-stood out in ways suggesting an altered molecular function likely to have biological implications. Firstly, they lack the ELR motif (amino acids Glu-Leu-Arg) in their N-terminus, a determining factor for chemokine targeting to CXCR1 and CXCR2 (Fig. 1). The ELR motif is conserved in all human chemokines targeting CXCR1 and CXCR2 [16] and is lacking in all chemokines targeting other chemokine receptors. It has been demonstrated, that introduction of an ELR motif in a non-ELR chemokine enables binding to CXCR1 and
CXCR2 [17], while a change to any of the three amino acids in an ELR chemokine abolishes its signaling capabilities through CXCR1 and CXCR2 [18]. Secondly, genotypes 5 and 6 have a nine amino acids long $\mathrm{N}$ terminus compared to the only four amino acid of the other UL146 genotypes (C. Berg et al. unpublished observations) (Fig. 1). The N-terminus of a chemokine is crucial for receptor binding and activation as confirmed by the solved structures of chemokine-bound chemokine receptors [19]. Thus, the chemokines encoded by UL146 genotypes 5 and 6 are distinct in ways likely to affect the receptor and host cell target, suggesting an altered biological function of these genotypes.

Previous studies have tried to establish a link between UL146 genotypes and cCMV without finding a clear association $[9,14,20,21]$. In addition, three studies have investigated whether severe cCMV was linked to specific UL146 genotypes by comparing symptomatic to asymptomatic cCMV cases, but no association was found [22-24]. These studies genotyped UL146 from mostly urine, but also saliva, amniotic fluid, and colon tissue, and were limited by small sample sizes. Another limitation was the lack of control groups representing CMV strains circulating in the background population of healthy individuals. In an attempt to address these problems, we first reasoned the sample size could be considerably increased by using neonatal dried blood spots (DBS) for UL146 genotyping. In many countries, a neonatal DBS is taken at birth for all newborns to screen for select hereditary diseases. These DBS are often stored in biobanks and their use in CCMV diagnosing has been suggested [25-28]. Therefore, we developed a highly efficient extraction and amplification protocol to permit UL146 genotyping from the limited amount of blood available in DBS [29]. Furthermore, we established a control group by screening urine samples from children with a suspected bacterial urine tract infection for CMV and genotyping UL146. Thus, by using the Danish civil registration number individually coupled to diagnoses in the Danish National Patient Registry and neonatal dried blood spots taken from all Danish newborns since 1982 stored in the Danish Neonatal Screening Biobank, we here investigate whether the non-ELR UL146 genotypes affect the development of cCMV disease in 116 infected neonates by comparing to a background population of strains derived from 83 children without CMV disease.

\section{Methods}

\section{Design, databases and study populations}

Free tax-funded healthcare is provided to all residents in Denmark. Every resident is assigned a personal identification number (civil registration number, CPR) and all use of healthcare services is reported to national 


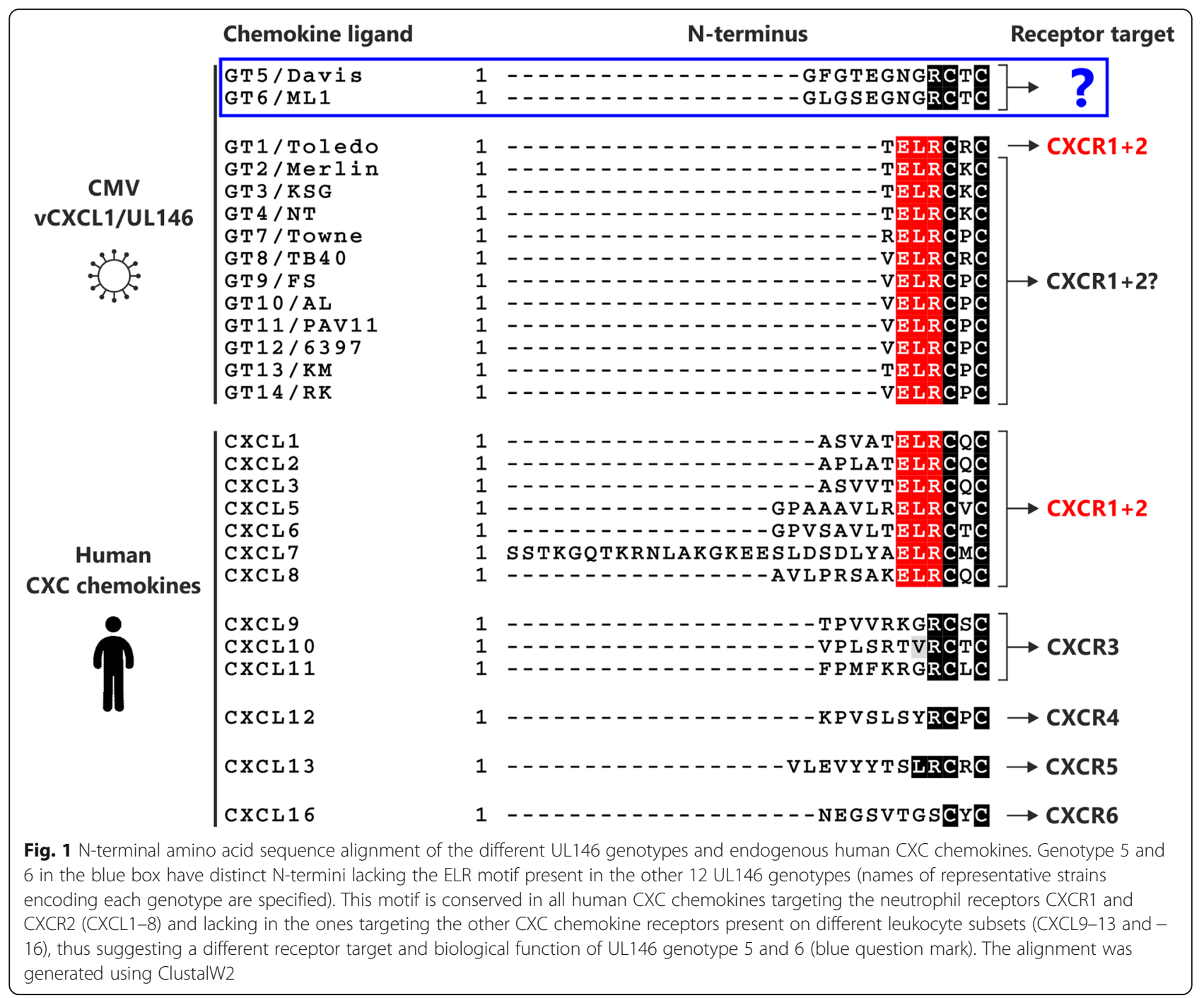

administrative databases [30]. The Danish National Patient Registry holds information about all hospital admissions and discharge diagnoses [31]. In a nationwide study, cases were identified and CPR-nos. Were extracted from the Danish National Patient Registry on neonates given a diagnosis of congenital CMV disease (diagnosis codes 07950 and DP351) from 1982 to 2018 and a diagnosis of non-hereditary hearing loss caused by CMV disease (diagnosis code DH918A3) from 2010 to 2018 using the International Classification of Diseases 8th and 10th revision. Discharge diagnoses are coded according to the International Classification of Disease (ICD) 8th revision through 1993 and the ICD 10th revision from 1994. The control group was established from urine samples sent to the Department for Microbiology at Herlev-Gentofte Hospital, Denmark, from children aged 1-8 with a suspected bacterial urinary tract infection. It was verified from microbiological databases that the controls were not under investigation for CMV and did not have any previous CMV tests performed. The samples were collected as anonymized excess clinical material.

\section{Ethics and data protection}

The study was approved by the National Committee on Health Research Ethics of the Capital Region of Denmark (record no. H-15017153) and by the Danish Data Protection Agency under the umbrella permit of the Capital Region of Denmark (record no. 2012-58-0004 with local record number VD-2018-101). Civil registration numbers on patients with congenital CMV disease and hearing loss caused by CMV were provided by The Danish Health Data Authority (Sundhedsdatastyrelsen).

\section{DNA extraction from dried blood spots and urine}

For all cases, two DBS punches each $3 \mathrm{~mm}$ in diameter were obtained from the Neonatal Screening Biobank in the Danish National Biobank. DNA was extracted as 
previously described [29], with the two DBS punches being incubated in $1000 \mu$ lysis buffer $(600 \mu$ l PBS BSA (0.04\%), $360 \mu \mathrm{l}$ Bacterial Lysis Buffer (Roche, Mannheim, Germany) and $40 \mu \mathrm{l}$ proteinase $\mathrm{K}$ (Roche) for $1 \mathrm{~h}$ at $55^{\circ} \mathrm{C}$ with continuous shaking at low speed. DNA was afterwards extracted from the lysate using a NucliSens easyMAG (bioMérieux) according to manufacturer guidelines using their Specific A protocol with an additional internal lysis step.

For the control group, group, DNA was extracted from $200 \mu \mathrm{l}$ urine using a NucliSens easyMAG (bioMérieux) according to manufacturer guidelines. The Specific A protocol was used with a final elution volume of $70 \mu \mathrm{l}$.

\section{Quantitative CMV PCR (qPCR)}

CMV viral titers (copies/ml) were quantified with the Rgene CMV kit (bioMérieux) according to the manufacturer's guidelines using a Rotor-gene Q (Qiagen) realtime PCR thermal cycler.

PCR amplification, purification, and sequencing of UL146 UL146 was PCR amplified, purified, and sequenced as previously described [29] with the exception that PCR of select low CMV titer samples used $10 \mu$ template instead of $5 \mu$ l. In details, the PCR mixture contained $1 \mathrm{X}$ Pfu DNA polymerase buffer with $2 \mathrm{mM} \mathrm{MgSO} 4,0.2 \mathrm{mM}$ dNTP (each, Qiagen, Hilden, Germany), $0.5 \mu \mathrm{M}$ of both forward (CCGGGAATACCGGATATTACG) and reverse primer (CAGCACTTCCTGACGATTG), and 1.25 U Pfu polymerase. The PCR amplification was performed using a ProFlex PCR System (Applied Biosystems, Foster City, USA) thermal cycler. An initial denaturation at $95^{\circ} \mathrm{C}$ for 2 min was followed by 40 cycles of denaturation at $95^{\circ} \mathrm{C}$ for $30 \mathrm{~s}$, annealing at $61^{\circ} \mathrm{C}$ for $30 \mathrm{~s}$, and elongation at $72^{\circ} \mathrm{C}$ for $2 \mathrm{~min}$ and finally $5 \mathrm{~min}$ of final elongation at $72{ }^{\circ} \mathrm{C}$. Samples were stored at $4{ }^{\circ} \mathrm{C}$ until analyzed by capillary electrophoresis. After amplification, $10 \mu \mathrm{l}$ of the PCR product was analyzed on a QIAxcel Advanced System (Qiagen) capillary electrophoresis system using the AM420 screening method, 15 $s$ injection time and one run per row. The QIAxcel DNA Screening kit (Qiagen) was used in combination with the QX Alignment marker $50 \mathrm{bp} / 5 \mathrm{~kb}$ (Qiagen) and QX Size marker $100 \mathrm{bp}-2.5 \mathrm{~kb}$ (Qiagen). Afterwards, the results were analyzed with the QIAxcel ScreenGel 1.6 software. Samples were purified using the MinElute PCR Purification kit (Qiagen) according to manufacturer instructions before they were Sanger-sequenced by GATC Biotech (Köln, Germany) using the same primers as for PCR amplification (both forward and reverse reads were obtained). Sequence reads were assembled and mapped to a reference sequence in Geneious Prime version 2019.1.3 and genotypes were manually identified. All sequences are available in GenBank under the accession nos. MN929769-MN929883 (cases) and MN929884MN929966 (controls).

\section{Statistics}

Statistical calculations were performed in RStudio version 1.1 and GraphPad Prism version 7. Fisher's exact test was performed when comparing genotype observations between the cases and controls. A two-tailed unpaired t-test was implemented to test the difference in viral load between male and female cases and a one-way ANOVA with Tukey's multiple comparison test between the different genotypes. Pearson's correlation was used investigate the correlation between and sample age and viral load, and any change was quantified by linear regression analysis.

\section{Phylogenetic analyses}

The phylogenetic analyses were performed in Geneious Prime 2019.1.3. Nucleotide and amino acid sequences were aligned separately using the ClustalW2 algorithm. Phylogenetic trees were generated by Tamura-Nei neighbor-joining of the nucleotide sequence alignment and Jukes-Cantor neighbor-joining of the amino acid sequence alignment. Both trees were resampled by bootstrapping with 1000 replicates and a support threshold of $0 \%$.

\section{Figures}

The chemokine $\mathrm{N}$-terminus alignment and the full sequence alignments were generated with ClustalW (genome.jp/toolsbin/clustalw) and BoxShade version 3.21 (embnet.vital-it.ch/ software/BOX_form.html), and the flow chart was created with Lucidchart (lucidchart.com). GraphPad Prism version 7 was used to generate the graphs. Figures were assembled in CorelDraw X6 version 16.

\section{Results \\ UL146 was successfully amplified from 116 out of 120 CMV-positive DBS samples}

From the Danish National Patient Registry [31], the personal identification numbers on all Danish patients given the 'congenital CMV' (cCMV) diagnosis since 1982 and the 'innate, non-hereditary hearing loss caused by CMV' (SNHL-CMV) diagnosis since 2010 were extracted (Fig. 2). Personal identification numbers were obtained on 336 patients in the cCMV group, 77 in the SNHLCMV group, and 38 who had both diagnoses. For the cCMV group, patients diagnosed more than 2 months after birth were excluded to reduce the risk of including post-natally infected neonates, with the exception of patients presenting with numerous hospital admissions under the cCMV diagnosis, resulting in $236 \mathrm{cCMV}$ patients fulfilling this inclusion criteria. Neonatal blood spots were requested from the Danish Neonatal 


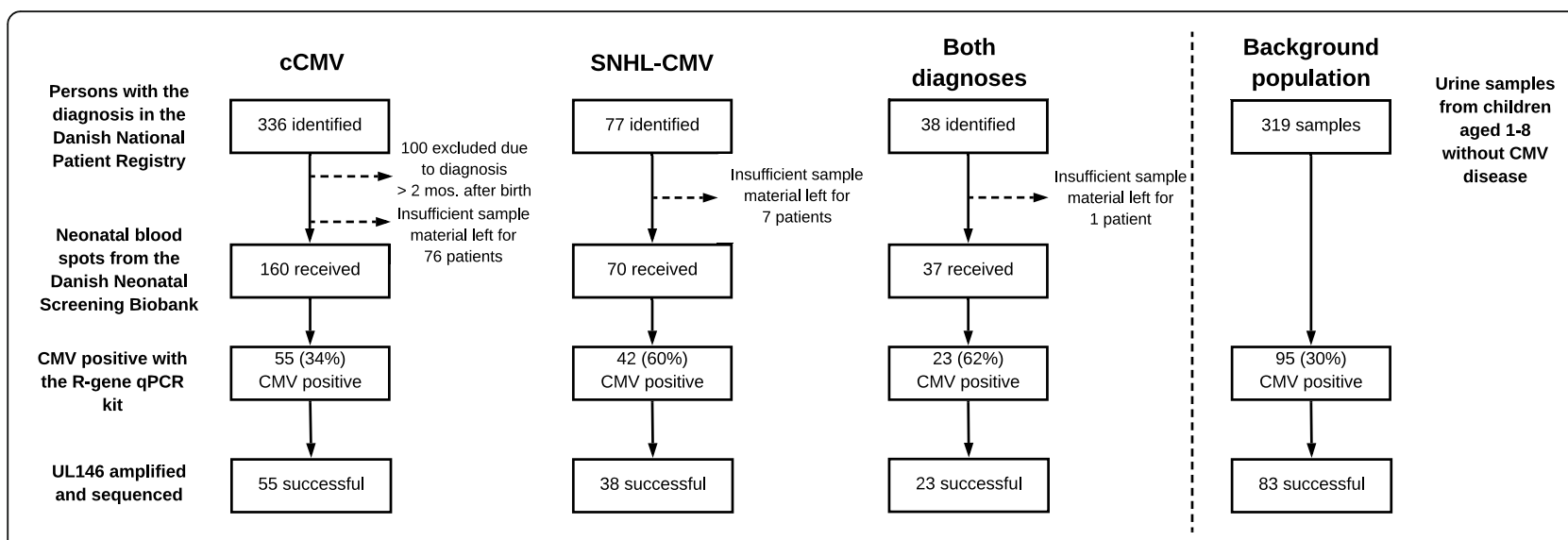

Fig. 2 Flow chart of study design and analyzed samples

Screening Biobank for all included patients. As some of the stored blood spots had either been used up over time or only little material reserved for diagnostics remained, the biobank was able to deliver blood spot punches on 160 neonates from the cCMV group, 70 from the SNHL-CMV group, and 37 from the group with both diagnoses. DNA was extracted from the samples and screened for CMV with the R-gene qPCR CMV kit, resulting in $55 \mathrm{CMV}$ positive samples in the cCMV group, 42 in the SNHL-CMV group, and 23 in the group with both diagnoses. Afterwards, UL146 was successfully PCR-amplified in 116 of the total 120 samples (97\%). The four failed reactions, all low titer samples belonging to the SNHL-CMV group, were repeated two additional times without success. To test if the UL146 PCR could detect $\mathrm{CMV}$ in $\mathrm{R}$-gene negative samples, we randomly selected 20 of these samples for PCR (10 cCMV and 10 SNHL), but all 20 were also found to be negative using the UL146 PCR. To establish a control group, we screened 319 random urine samples from children without a suspected CMV infection aged 1-8 for CMV, resulting in 95 (30\%) CMV-positive samples and UL146 was successfully PCR-amplified and sequenced in 83 of them.

The frequency of non-ELR UL146 genotypes in registered CCMV cases does not differ from the control group

UL146 was sequenced and a phylogenetic analysis of the genotype distribution was performed (Fig. 3). All 199 sequences (116 cases and 83 controls) were found to cluster accordingly with the previously described genotypes [14] for both nucleotide (Fig. 3a) and amino acid sequences (Fig. 3b) and showed very little intra-genotype variation. Among the CMV patients, the overall frequency of non-ELR UL146 genotypes (genotype 5 and 6) was $2.6 \%(3 / 116)$ with all three strains encoding genotype 5 (Table 1$)$, while two $(2 / 83,2.4 \%)$ were observed in the control group. Fisher's exact test was performed with no significant outcome for genotype 5 and 6 between the groups $(P>0.99)$. Thus, non-ELR genotypes were not found to be associated with CMV disease in neonates.

\section{Analysis of the ELR genotype distribution between CCMV cases and the control group}

Among the ELR genotypes in the case group, genotype 12 was the most frequent and observed in $32 \%$ of the strains and together with genotype $13(16 \%)$ and genotype $8(10 \%)$ they accounted for $58 \%$ of the sequences (Table 1). There was no significant difference in the genotype distribution within the group of congenitally infected neonates or compared to the control group using Fisher's exact test. The largest discrepancy found between cases and controls were for genotype 1 with 5 cases (4.3\%) and 9 controls (10.8\%) and genotype 8 with 12 cases $(10.3 \%)$ and three control (3.6\%), with a $P$ values of 0.09 and 0.10 , respectively.

\section{Analysis of intra-genotype variation between strains from cCMV cases and controls}

After post hoc analysis for association of specific genotypes with cCMV infection, we investigated whether intra-genotype differences could be associated with cCMV. All amino acid sequences for each UL146 genotype were aligned in order to analyze differences in intra-genotype distributions between strains from cCMV cases and controls of the translated gene (Supplemental data and Table S1). We found two deletions and ten non-conservative mutations appearing more than once in only five strains (Table 2). The frequencies of each mutation/deletion showed no association with cCMV. 

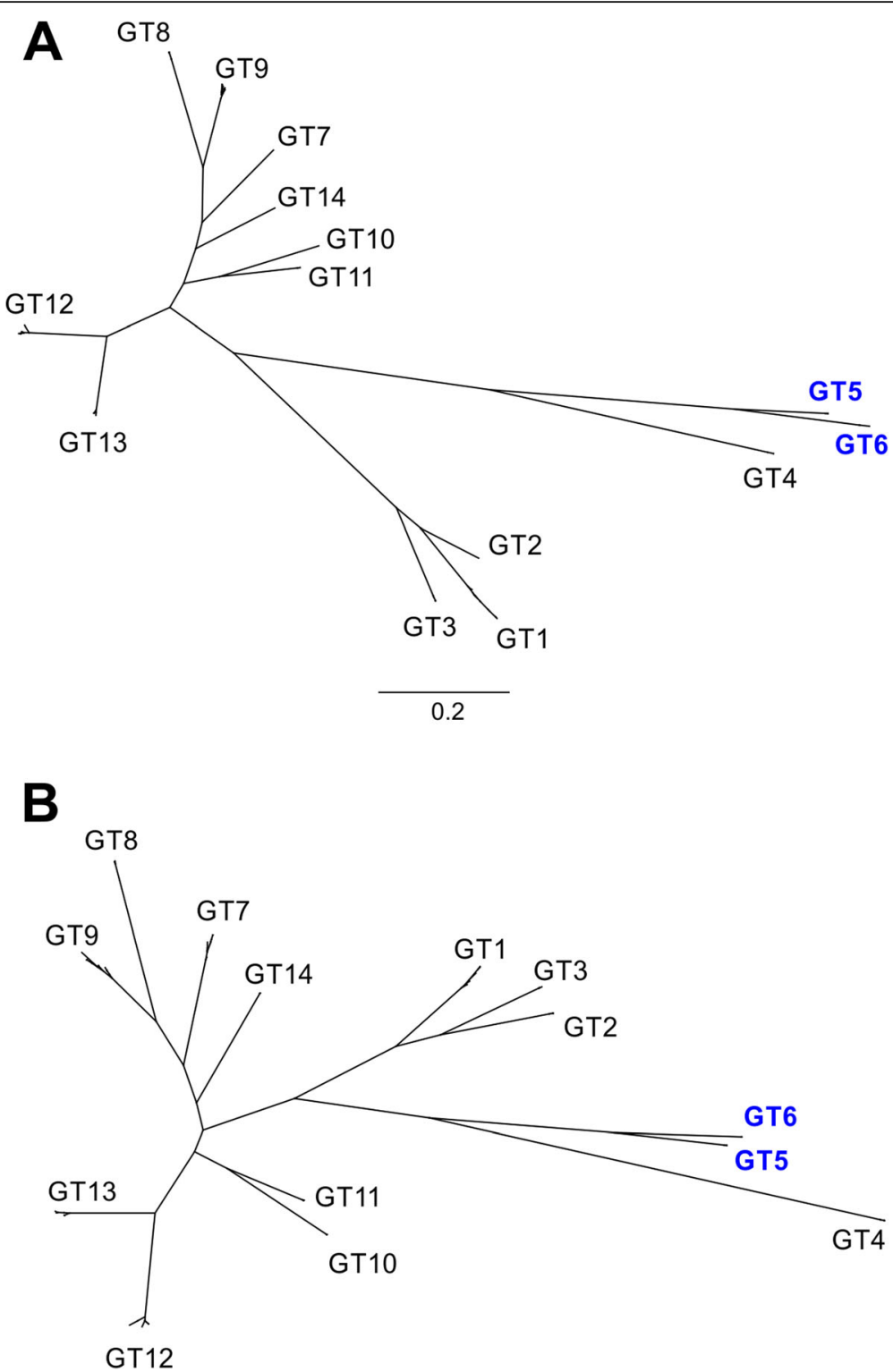

0.2

Fig. 3 Phylogenetic trees of 198 UL146 nucleotide and amino acid sequences from the cases and controls. a Tamura-Nei neighbor-joining of 198 UL146 nucleotide sequences from cases and controls with the 14 previously described genotypes [14]. $\mathbf{b}$ Jukes-Cantor neighbor-joining of the translated amino acid sequences. One partial genotype 7 sequence was excluded from the tree generation. Trees were resampled by bootstrapping with 1000 replicates. Distance scale presented in substitutions per site

The CMV-positive rate was higher amongst the SNHLCMV group than the cCMV group

Overall, 120 of the 267 (45\%) blood spots tested positive for $\mathrm{CMV}$, revealing a large portion of the samples from registered CMV cases not containing measurable amounts CMV DNA. The positive rate was different between the two diagnoses at 34\% (55/160) for cCMV and $60 \%(42 / 70)$ for SNHL-CMV, which was a highly significant difference $(P=0.0005)$ using Fisher's exact test.
Viral titer in CCMV is not associated with UL146 genotype or gender, and not correlated with sample age

We did not observe any significant association between CMV titer in the CCMV cases and UL146 genotype in a one-way ANOVA with Tukey's multiple comparison test (Fig. 4a). We observed an equal number of CMVpositive male and female patients with 60 of each gender and found no significant association between gender and CMV titer in a two-tailed unpaired t-test $(P=0.58)$ after logarithm-transformation of viral titer to achieve a 
Table 1 Distribution of UL146 genotypes in case and control groups

\begin{tabular}{|c|c|c|c|c|c|c|c|c|c|c|c|}
\hline \multirow[t]{3}{*}{ Genotype } & \multicolumn{6}{|c|}{ CMV diagnoses } & \multirow{2}{*}{\multicolumn{2}{|c|}{$\begin{array}{l}\text { Total case CMV } \\
\text { strains }\end{array}$}} & \multirow{2}{*}{\multicolumn{2}{|c|}{$\begin{array}{l}\text { Control CMV } \\
\text { strains }\end{array}$}} & \multirow{3}{*}{$\begin{array}{l}P \\
\text { value }\end{array}$} \\
\hline & \multicolumn{2}{|c|}{ cCMV } & \multicolumn{2}{|c|}{ SNHL-CMV } & \multicolumn{2}{|c|}{ cCMV + SNHL-CMV } & & & & & \\
\hline & $n$ & $f(\%)$ & $n$ & $f(\%)$ & $n$ & $f(\%)$ & $n$ & $f(\%)$ & $n$ & $f(\%)$ & \\
\hline GT1 & 2 & 3.6 & 3 & 7.9 & 0 & 0.0 & 5 & 4.3 & 9 & 10.8 & 0.09 \\
\hline GT2 & 5 & 9.1 & 1 & 2.6 & 3 & 13.0 & 9 & 7.8 & 3 & 3.6 & 0.37 \\
\hline GT3 & 0 & 0.0 & 1 & 2.6 & 1 & 4.3 & 2 & 1.7 & 2 & 2.4 & $>0.99$ \\
\hline GT4 & 1 & 1.8 & 1 & 2.6 & 0 & 0.0 & 2 & 1.7 & 2 & 2.4 & $>0.99$ \\
\hline GT5 & 1 & 1.8 & 1 & 2.6 & 1 & 4.3 & 3 & 2.6 & 0 & 0.0 & 0.27 \\
\hline GT6 & 0 & 0.0 & 0 & 0.0 & 0 & 0.0 & 0 & 0.0 & 2 & 2.4 & 0.17 \\
\hline GT7 & 5 & 9.1 & 2 & 5.3 & 0 & 0.0 & 7 & 6.0 & 8 & 9.6 & 0.42 \\
\hline GT8 & 7 & 12.7 & 2 & 5.3 & 3 & 13.0 & 12 & 10.3 & 3 & 3.6 & 0.10 \\
\hline GT9 & 7 & 12.7 & 2 & 5.3 & 2 & 8.7 & 11 & 9.5 & 8 & 9.6 & $>0.99$ \\
\hline GT10 & 1 & 1.8 & 2 & 5.3 & 0 & 0.0 & 3 & 2.6 & 2 & 2.4 & $>0.99$ \\
\hline GT11 & 1 & 1.8 & 3 & 7.9 & 0 & 0.0 & 4 & 3.4 & 3 & 3.6 & $>0.99$ \\
\hline GT12 & 14 & 25.5 & 13 & 34.2 & 10 & 43.5 & 37 & 31.9 & 26 & 31.3 & $>0.99$ \\
\hline GT13 & 9 & 16.4 & 6 & 15.8 & 3 & 13.0 & 18 & 15.5 & 12 & 14.5 & $>0.99$ \\
\hline GT14 & 2 & 3.6 & 1 & 2.6 & 0 & 0.0 & 3 & 2.6 & 3 & 3.6 & 0.70 \\
\hline Total & 55 & 100.0 & 38 & 100.0 & 23 & 100.0 & 116 & 100.0 & 83 & 100.0 & \\
\hline
\end{tabular}

$P$-value calculated using Fisher's exact test between total observations among CMV cases compared to the controls

Gaussian distribution (Fig. 4b). Despite expecting the DNA in the DBS samples to degrade over time, sample age was not found to be significantly correlated with viral titer $(P=0.079$ and $r=-0.16[-0.33,0.02])$ using Pearson's correlation after logarithm-transformation of age in months and virus titer (Fig. 4c) with linear regression giving a slope of $-0.014 \pm 0.008$ SE.

\section{Discussion}

Circulating CMV strains exhibit a high degree of genetic diversity unparalleled by other human herpesviruses $[8,9]$ that affects important immunomodulators. These observations have raised the question of whether specific CMV strains have different pathogenic potential, however, current information has proven insufficient to demonstrate a clear link. UL146 is one of the most diverse CMV genes, encoding a CXC chemokine with 14 distinct genotypes that potentially have different biological functions. Using a control group of circulating CMV strains from the background population, we found no association between the two UL146 genotypes lacking the ELR-motif (genotypes 5 and 6) otherwise conserved in the 12 other

Table 2 Observed deletions and non-conservative intra-genotype variations among 198 amino acid sequences

\begin{tabular}{|c|c|c|c|c|}
\hline \multirow[t]{2}{*}{ Genotype } & \multicolumn{2}{|l|}{ Intra-genotype variation } & \multicolumn{2}{|l|}{ Frequencies } \\
\hline & Non-conservative mutation & Deletion & Case strains & Control strains \\
\hline \multirow[t]{6}{*}{$\overline{\mathrm{GT} 1}$} & & G71-G72 & $2 / 4$ & $3 / 9$ \\
\hline & $\mathrm{P} 72 \mathrm{H}$ & & $0 / 4$ & $2 / 9$ \\
\hline & Y89R & & $0 / 4$ & $2 / 9$ \\
\hline & Y89H & & $2 / 4$ & $4 / 9$ \\
\hline & G104E & & $0 / 4$ & $2 / 9$ \\
\hline & R116G & & $2 / 4$ & $3 / 9$ \\
\hline \multirow[t]{3}{*}{ GT9 } & W41L & & $4 / 11$ & $2 / 8$ \\
\hline & W60L & & $4 / 11$ & $4 / 8$ \\
\hline & D98G & & $4 / 11$ & $3 / 8$ \\
\hline GT11 & & G100 & $2 / 4$ & $0 / 3$ \\
\hline GT12 & G55E & & $13 / 37$ & $12 / 26$ \\
\hline GT13 & G32N & & $2 / 19$ & $2 / 11$ \\
\hline
\end{tabular}

Only deletions and non-conservative mutations appearing more than once are shown. 

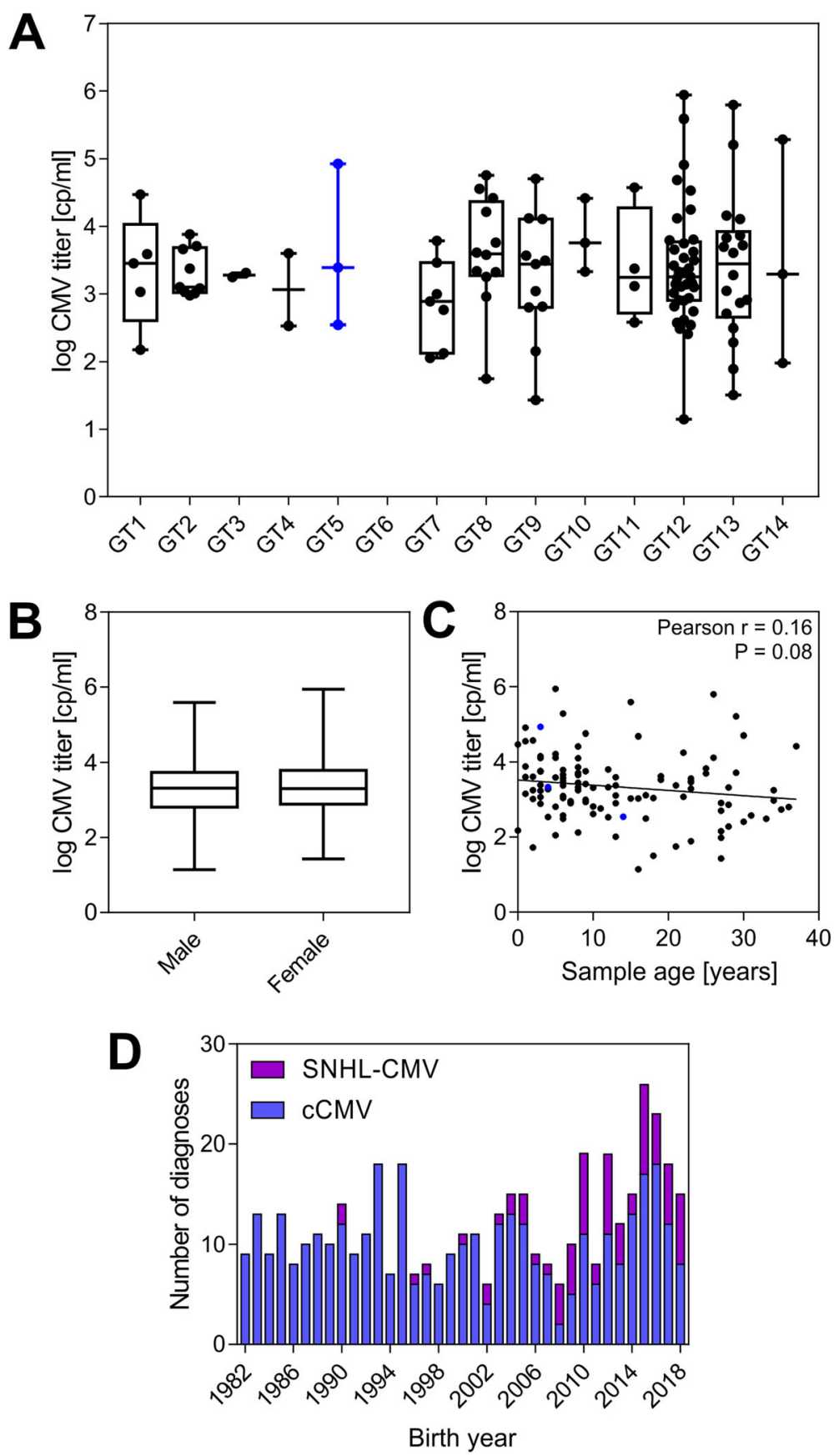

Fig. 4 Analysis of viral titer association with UL146 genotype, gender, and sample age. a Box-whisker plot of sample CMV titer and the UL146 genotype found in the sample. Non-ELR UL146 genotypes are marked in blue. No significant differences were found in a one-way ANOVA with Tukey's multiple comparison test, $n=116$. b Box-whisker plot of sample CMV titer and gender showing no association, $n=120$. c Scatter plot of sample age and CMV titer with a linear regression line showing no significant correlation, $n=120$. Non-ELR UL146 genotypes are marked in blue. d Congenital CMV diagnoses over the study period per birth year for a total of 451 registered cases

genotypes and the development of cCMV disease in neonates.

We genotyped UL146 in a total of 116 CMV positive DBS samples from neonates with CCMV or SNHL-CMV and in 83 samples from children without a history of CMV disease. We observed three genotype 5 strains and no genotype 6 strains in the case group (one in each sub-group of cCMV, SNHL-CMV, and both diagnoses), while two genotype 6 and no genotype 5 strains were observed in the control group, a difference that was not found to be significant. The $2.6 \%$ frequency $(3 / 116)$ of genotype 5 and 6 strains found in neonates in our study 
did not differ from frequencies found in other studies, which were in the range from 0 to $4.5 \%[9,14,21-24]$. This study is yet the largest among UL146 genotyping studies from neonates with cCMV [9, 14, 20-24] and, to our knowledge, the only one with an established control group for comparison of genotype prevalence between patients and the background population. The lack of control groups in previous studies have made it difficult to determine whether the reported prevalence of non-ELR UL146 genotypes in neonates with cCMV is different from the strains circulating in the background population of the particular geographical area. However, there are potential caveats to the comparison of cases and controls. A study sampled longitudinal genomic populations from the urine and plasma of five infants with symptomatic congenital CMV infection. They found that samples from different compartments taken at the same time were more variable than samples from the same compartment taken over time. The data were consistent with models with several bottlenecks and phases of rapid expansion of the viral populations driving viral selection. Furthermore, they found that positive selection played a small role in viral evolution within a compartment in contrast to a strong role and pervasive driver of evolution associated with compartmentalization [32]. Thus, a possible difference in genotypes between cases and controls could also be interpreted as comparing sequences from viral populations drawn from different compartments, i.e. blood and urine, or from comparing sequences from compartments with a high and low viral load. However, no mutations in the UL146 gene between compartments or over time were reported. Likewise, we did not find any inter- or intra-genotypic differences in frequencies of UL146 between the cases and controls (Tables 1 and 2). Though we cannot exclude that genotypes found in children's urine are not fully representative for strains circulating in the background population, we find it to be a very close approximation as the strains found in childhood remain throughout adult life as CMV establishes latency. Finally, we cannot rule out that non-ELR UL146 genotypes are a pathogenic factor for development of symptomatic or severe cCMV disease as no medical chart information was obtained, making it impossible to discern the severity of CMV disease between the cases. This study limitation was accepted early on as recent changes in national patient data security regulations required medical chart review to be carried out in local collaborations with doctors from each hospital having treated the patients dating back to 1982, which was not considered feasible. However, as symptomatic cCMV cases are expected to represent a significant part of neonates with a cCMV diagnosis and the prevalence of non-ELR genotypes was low $(2.6 \%)$, it is not expected that chart review would have changed the conclusions of this report. Post hoc analyses for the other genotypes were performed and the overall genotype distribution was found to be similar between the patient groups and the control population with no significant differences. Furthermore, there was no observable difference in viral load between different UL146 genotypes, which to our knowledge has not been investigated previously. A second limitation is that Sanger sequencing is not suited for detection of multiple UL146 genotypes in mixed CMV infections. However, next generation sequencing has shown that mixed UL146 genotypes are found in just $2 \%$ of congenital CMV infections and that multiple CMV strains are infrequently found in congenital infection (14\%) [9]. Moreover, NGS performed on enriched target material requires a substantial viral load for full genome coverage. Thus, target enriched HIV samples showed full coverage of the $10 \mathrm{~kb}$ HIV genome in $80 \%$ of samples with viral load above $3100 \mathrm{cp} / \mathrm{ml}$ equivalent to a target input of 1500 viral copies [33]. For comparison, the median viral load in blood in congenital CMV infection has been reported to be $2300 \mathrm{cp} / \mathrm{ml}$ [34], equivalent to a DBS target input of approximately 14 copies (from two $\sim 3 \mu$ l punches), which would suggest a lower sensitivity for UL146 genotyping by NGS than seen for Sanger sequenced PCR products. Thirdly, the use of only one PCR reaction per sample can have allowed for rare polymerase introduced mutations, which could give rise to false positive intra-genotypic mutations. Although the error rate of the Pfu polymerase is low, estimated to approx. 1:1000,000 bp, and any minor random error was not likely to affect the manual genotyping of UL146. However for this reason, only deletions and non-conservative mutations appearing more than once are shown in Table 2.

Interestingly, only 451 cases of congenital CMV disease (336 cCMV + 77 SNHL-CMV cases + 38 with both diagnoses) had been registered in Denmark since 1982 with just 267 relevant samples available-much lower than the number expected from reported incidence rates. Assuming a live birth rate of approximately 60.000 per year in Denmark (based on the numbers published by Statistics Denmark) and a cCMV incidence of $0.5 \%$ with $10 \%$ symptomatic cases, 30 symptomatic cases per year was expected, or 1080 symptomatic cases over the 36 year period, plus a larger number of asymptomatic cases. There was no change in number of diagnosed cCMV cases over this period (Fig. 4d), averaging to 10 cases per year. This suggests that $\mathrm{CCMV}$ disease is underreported or underdiagnosed in Denmark. 
We were able to detect CMV in $45 \%$ of the 267 DBS samples upon screening with the R-gene qPCR CMV kit and found a significantly higher positive rate among samples from neonates with a SNHL-CMV diagnosis compared to those with a cCMV diagnosis. This could be a reflection of the sensitivity of the methods used to extract and detect CMV in the dried blood spots. Sensitivity is a valid concern when using DBS for pathogen detection as only $\sim 6 \mu \mathrm{l}$ dried blood was obtainable from each patient. Despite the extraction protocol being optimized for up to $100 \%$ recovery efficiency [29] and the R-gene kit having a high sensitivity $\left(\mathrm{LoD}_{95 \%}\right.$ of 555 copies $/ \mathrm{ml}$ and $\mathrm{LoD}_{5 \%}$ of 30 copy $/ \mathrm{ml}$ ), the $6 \mu \mathrm{l}$ dried blood was diluted during DNA extraction which allowed for cases with very low viral loads to avoid detection. In previous studies, the sensitivity for detecting CMV in DBS from neonates with confirmed $\mathrm{CCMV}$ by urine/saliva analysis has shown variation depending on the study design. One study found $100 \%$ sensitivity for 72 cCMV cases using a relatively large sample volume [35], while another three studies reported sensitivities from 70 to $75 \%$ among 55, 70, and 103 cCMV cases [26, 36, 37] which agrees with a report that $75 \%$ of cCMV cases are viraemic at birth [38], and a fifth group found a lower sensitivity of $34 \%$ for $91 \mathrm{cCMV}$ cases [27] that the authors explain as being related to DNA extraction and PCR. However, all undetectable cases are likely not accounted for by the sensitivity of the assay as there was a significant difference between the subgroups of neonates with a cCMV diagnosis and those with a SNHL-CMV diagnosis in our study. Thus, several factors are likely to influence the positive rate in the case groups. Firstly, the sensitivity of extraction and PCR, as low and non-viraemic cases could be missed. Secondly, the diagnostic precision, as cases could not be validated without chart review. And thirdly, the timing of infection, as the cCMV diagnosis may have been given due to active infection of the mother during pregnancy and not of the child at birth.

\section{Conclusions}

We sequenced UL146 in 116 DBS samples from neonates with CCMV disease, compared the results to 83 samples from the background population, and did not find an association between specific UL146 genotypes and cCMV disease. As studies have shown that circulating CMV strains contain disruptions of more than 25 genes and have at least 30 polymorphic genes [8, 9], each of these individual genes as well as a mix of viral and host factors should be investigated as a whole in future studies looking for an association between genetic content and clinical endpoints.

\section{Abbreviations}

CMV: Cytomegalovirus; cCMV: Congenital cytomegalovirus disease; SNHL: Sensorineural hearing-loss; ELR: Amino acid Glu-Leu-Arg; DBS: Dried blood spot; CPR: Civil registration number

\section{Supplementary Information}

The online version contains supplementary material available at https://doi. org/10.1186/s12879-021-06076-w.

\section{Additional file 1. \\ Additional file 2}

\section{Acknowledgments}

The authors would like to acknowledge Head of Department, MD Finn Rønholt (Department of Medicine, Herlev-Gentofte Hospital, Denmark) for financial support, and Head of Department, MD, DMSc Jens Otto Jarløv (Department of Clinical Microbiology, Herlev-Gentofte Hospital, Denmark) for providing the facilities for the study.

\section{Authors' contributions}

$C B, L N$ and $H L$ designed the study. CB, TB and $H L$ applied for applicable study approvals. CB and TS performed the experimental work. CB and $\mathrm{HL}$ analyzed the data and prepared the manuscript. CB, MR and HL applied for study funding. The study was managed by HL. All authors revised and edited the manuscript, and all authors have read and approved the final manuscript.

\section{Funding}

The study was in part funded by the University of Copenhagen (Denmark), the Department of Medicine (Herlev-Gentofte Hospital, Denmark), the Department of Clinical Microbiology (Herlev-Gentofte Hospital, Denmark), Synklino, Herlev and Gentofte Hospital's Research Council, Carl and Ellen Hertz Grant, Christian Larsen and Judge Ellen Larsen's Grant, Dagmar Marshall's Foundation, the Hartmann Foundation, and the A.P. Møller Foundation for the Promotion of the Medical Science.

Founding bodies had no role in the design of the study and collection, analysis, and interpretation of data and in writing of the manuscript.

\section{Availability of data and materials}

Patient identifiers were provided by The Danish Health Data Authority and data were extracted from the Danish National Patient Registry following study and data acquisition approval (see relevant permission obtained under "Ethical approval" above).

All UL146 sequences generated in the study are available in GenBank (https://www.ncbi.nlm.nih.gov/genbank/) under the accession nos. MN929769-MN929883 (cases, https://www.ncbi.nlm.nih.gov/popset/?term= 1928703183) and MN929884-MN929966 (controls, https://www.ncbi.nlm.nih. gov/popset/?term=1928703413). All other datasets used and/or analyzed in the study are available from the corresponding authors upon reasonable request.

\section{Declarations}

Consents for publication

Not applicable.

Ethics approval and consent to participate

The study was approved by the National Committee on Health Research Ethics of the Capital Region of Denmark (record no. H-15017153) and by the Danish Data Protection Agency under the umbrella permit of the Capital Region of Denmark (record no. 2012-58-0004 with local record number VD2018-101).

Competing interests

The authors declare to have no competing interests. 


\section{Author details}

'Infectious Diseases Unit, Department of Medicine, Copenhagen University Hospital, Herlev Gentofte, DK-2730 Herlev, Denmark. ${ }^{2}$ Center for Research and Disruption of Infectious Diseases (CREDID), Department of Infectious Diseases, Copenhagen University Hospital, Amager Hvidovre, DK-2650 Hvidovre, Denmark. ${ }^{3}$ Laboratory for Molecular Pharmacology, Department of Biomedical Sciences, Faculty of Health and Medical Sciences, University of Copenhagen, DK-2200 Copenhagen, Denmark. ${ }^{4}$ Department of Clinical Microbiology, Copenhagen University Hospital, Herlev Gentofte, DK-2730 Herlev, Denmark.

\section{Received: 5 October 2020 Accepted: 15 April 2021} Published online: 26 April 2021

\section{References}

1. Cannon MJ, Schmid DS, Hyde TB. Review of cytomegalovirus seroprevalence and demographic characteristics associated with infection. Rev Med Virol. 2010;20(4):202-13. https://doi.org/10.1002/rmv.655.

2. Noyola DE, Valdez-Lopez BH, Hernandez-Salinas AE, Santos-Diaz MA, Noyola-Frias MA, Reyes-Macias JF, et al. Cytomegalovirus excretion in children attending day-care centers. Arch Med Res. 2005;36(5):590-3. https://doi.org/10.1016/j.arcmed.2005.03.045.

3. Grosjean J, Trapes L, Hantz S, Mengelle C, Virey B, Undreiner F, et al. Human cytomegalovirus quantification in toddlers saliva from day care centers and emergency unit: a feasibility study. J Clin Virol. 2014;61(3):371-7. https://doi. org/10.1016/j.jcv.2014.07.020

4. Amin MM, Bialek SR, Dollard SC, Wang C. Urinary Cytomegalovirus shedding in the United States: the National Health and nutrition examination surveys, 1999-2004. Clin Infect Dis. 2018;67(4):587-92. https://doi.org/10.1093/cid/ ciy 143.

5. Dollard SC, Grosse SD, Ross DS. New estimates of the prevalence of neurological and sensory sequelae and mortality associated with congenital cytomegalovirus infection. Rev Med Virol. 2007;17(5):355-63. https://doi. org/10.1002/rmv.544.

6. Kenneson A, Cannon MJ. Review and meta-analysis of the epidemiology of congenital cytomegalovirus (CMV) infection. Rev Med Virol. 2007;17(4):25376. https://doi.org/10.1002/rmv.535.

7. Institute of Medicine Committee to Study Priorities for Vaccine D. The National Academies Collection: Reports funded by National Institutes of Health. In: Stratton KR, Durch JS, Lawrence RS, editors. Vaccines for the $21 \mathrm{st}$ Century: A Tool for Decisionmaking. Washington (DC): National Academies Press (US). Copyright 2000 by the National Academy of Sciences. All rights reserved; 2000.

8. Sijmons S, Thys K, Mbong Ngwese M, Van Damme E, Dvorak J, Van Loock $M$, et al. High-throughput analysis of human cytomegalovirus genome diversity highlights the widespread occurrence of gene-disrupting mutations and pervasive recombination. J Virol. 2015;89(15):7673-95. https://doi.org/10.1128/JVl.00578-15.

9. Suarez NM, Wilkie GS, Hage E, Camiolo S, Holton M, Hughes J, et al. Human cytomegalovirus genomes sequenced directly from clinical material: variation, multiple-strain infection, recombination, and gene loss. J Infect Dis. 2019;220(5):781-91. https://doi.org/10.1093/infdis/jiz208.

10. Luttichau HR. The cytomegalovirus UL146 gene product VCXCL1 targets both CXCR1 and CXCR2 as an agonist. J Biol Chem. 2010;285(12):9137-46. https://doi.org/10.1074/jbc.M109.002774.

11. Penfold ME, Dairaghi DJ, Duke GM, Saederup N, Mocarski ES, Kemble GW, et al. Cytomegalovirus encodes a potent alpha chemokine. Proc Natl Acad Sci U S A. 1999;96(17):9839-44. https://doi.org/10.1073/pnas.96.17.9839.

12. Cha TA, Tom E, Kemble GW, Duke GM, Mocarski ES, Spaete RR. Human cytomegalovirus clinical isolates carry at least 19 genes not found in laboratory strains. J Virol. 1996;70(1):78-83. https://doi.org/10.1128/JVI.70.1. 78-83.1996.

13. Jackson JW, Hancock TJ, LaPrade E, Dogra P, Gann ER, Masi TJ, et al. The human cytomegalovirus chemokine vcxcl-1 modulates normal dissemination kinetics of murine cytomegalovirus In Vivo. mBio. 2019;10(3): e01289-19. https://doi.org/10.1128/mBio.01289-19.

14. Dolan A, Cunningham C, Hector RD, Hassan-Walker AF, Lee L, Addison C, et al. Genetic content of wild-type human cytomegalovirus. J Gen Virol. 2004;85(Pt 5):1301-12. https://doi.org/10.1099/vir.0.79888-0.

15. Heo J, Dogra P, Masi TJ, Pitt EA, de Kruijf P, Smit MJ, et al. Novel human cytomegalovirus viral chemokines, VCXCL-1s, display functional selectivity for neutrophil signaling and function. J Immunol. 2015;195(1):227-36. https://doi.org/10.4049/jimmunol.1400291.

16. Bachelerie F, Ben-Baruch A, Burkhardt AM, Combadiere C, Farber JM, Graham GJ, et al. International Union of Basic and Clinical Pharmacology. [corrected]. LXXXIX. Update on the extended family of chemokine receptors and introducing a new nomenclature for atypical chemokine receptors. Pharmacol Rev. 2014;66(1):1-79. https://doi.org/10.1124/pr.113.007724.

17. Clark-Lewis I, Dewald B, Geiser T, Moser B, Baggiolini M. Platelet factor 4 binds to interleukin 8 receptors and activates neutrophils when its $N$ terminus is modified with Glu-Leu-Arg. Proc Natl Acad Sci U S A. 1993;90(8): 3574-7. https://doi.org/10.1073/pnas.90.8.3574.

18. Hebert CA, Vitangcol RV, Baker JB. Scanning mutagenesis of interleukin-8 identifies a cluster of residues required for receptor binding. J Biol Chem. 1991;266(28):18989-94. https://doi.org/10.1016/S0021-9258(18)55160-7.

19. Kufareva I, Gustavsson M, Zheng Y, Stephens BS, Handel TM. What do structures tell us about chemokine receptor function and antagonism? Annu Rev Biophys. 2017;46(1):175-98. https://doi.org/10.1146/annurevbiophys-051013-022942.

20. Paradowska E, Jablonska A, Plociennikowska A, Studzinska M, Suski P, Wisniewska-Ligier $M$, et al. Cytomegalovirus alpha-chemokine genotypes are associated with clinical manifestations in children with congenital or postnatal infections. Virology. 2014;462-463:207-17.

21. Guo G, Zhang L, Ye S, Hu Y, Li B, Sun X, et al. Polymorphisms and features of cytomegalovirus UL144 and UL146 in congenitally infected neonates with hepatic involvement. PLoS One. 2017;12(2):e0171959. https://doi.org/1 0.1371/journal.pone.0171959.

22. Arav-Boger R, Foster CB, Zong JC, Pass RF. Human cytomegalovirusencoded alpha -chemokines exhibit high sequence variability in congenitally infected newborns. J Infect Dis. 2006;193(6):788-91. https://doi. org/10.1086/500508.

23. He R, Ruan Q, Qi Y, Ma YP, Huang YJ, Sun ZR, et al. Sequence variability of human cytomegalovirus UL146 and UL147 genes in low-passage clinical isolates. Intervirology. 2006;49(4):215-23. https://doi.org/10.1159/000091468.

24. Heo J, Petheram S, Demmler G, Murph JR, Adler SP, Bale J, et al. Polymorphisms within human cytomegalovirus chemokine (UL146/UL147) and cytokine receptor genes (UL144) are not predictive of sequelae in congenitally infected children. Virology. 2008;378(1):86-96. https://doi.org/1 0.1016/j.virol.2008.05.002.

25. Barbi M, Binda S, Caroppo S. Diagnosis of congenital CMV infection via dried blood spots. Rev Med Virol. 2006;16(6):385-92. https://doi.org/10.1002/ rmv.517.

26. Atkinson C, Walter S, Sharland M, Tookey P, Luck S, Peckham C, et al. Use of stored dried blood spots for retrospective diagnosis of congenital CMV. JMedVirol. 2009;81(8):1394-8.

27. Boppana SB, Ross SA, Novak Z, Shimamura M, Tolan RW Jr, Palmer AL, et al. Dried blood spot real-time polymerase chain reaction assays to screen newborns for congenital cytomegalovirus infection. JAMA. 2010;303(14): 1375-82. https://doi.org/10.1001/jama.2010.423.

28. Pellegrinelli L, Galli C, Primache V, Alde M, Fagnani E, Di Berardino F, et al. Diagnosis of congenital CMV infection via DBS samples testing and neonatal hearing screening: an observational study in Italy. BMC Infect Dis. 2019;19(1):652. https://doi.org/10.1186/s12879-019-4296-5.

29. Berg C, Friis MB, Rosenkilde MM, Benfield T, Nielsen L, Luttichau HR, et al. Development of highly efficient protocols for extraction and amplification of cytomegalovirus DNA from dried blood spots for detection and genotyping of polymorphic immunomodulatory genes. PLoS One. 2019; 14(9):e0222053. https://doi.org/10.1371/journal.pone.0222053.

30. Pedersen CB, Gotzsche H, Moller JO, Mortensen PB. The Danish civil registration system. A cohort of eight million persons. Dan Med Bull. 2006; 53(4):441-9

31. Lynge E, Sandegaard JL, Rebolj M. The Danish National Patient Register. Scand J Public Health. 2011;39(7 Suppl):30-3. https://doi.org/10.1177/14034 94811401482.

32. Renzette N, Gibson L, Bhattacharjee B, Fisher D, Schleiss MR, Jensen JD, et al. Rapid intrahost evolution of human cytomegalovirus is shaped by demography and positive selection. PLoS Genet. 2013;9(9):e1003735. https:// doi.org/10.1371/journal.pgen.1003735.

33. Yamaguchi J, Olivo A, Laeyendecker O, Forberg K, Ndembi N, Mbanya D, et al. Universal target capture of HIV sequences from NGS libraries. Front Microbiol. 2018;9:2150. https://doi.org/10.3389/fmicb.2018.02150. 
34. Halwachs-Baumann G, Genser B, Pailer S, Engele H, Rosegger H, Schalk A, et al. Human cytomegalovirus load in various body fluids of congenitally infected newborns. J Clin Virol. 2002;25(Suppl 3):S81-7.

35. Barbi M, Binda S, Primache V, Caroppo S, Dido P, Guidotti P, et al. Cytomegalovirus DNA detection in Guthrie cards: a powerful tool for diagnosing congenital infection. JClinVirol. 2000;17(3):159-65.

36. Soetens O, Vauloup-Fellous C, Foulon I, Dubreuil P, De SB, Grangeot-Keros L, et al. Evaluation of different cytomegalovirus (CMV) DNA PCR protocols for analysis of dried blood spots from consecutive cases of neonates with congenital CMV infections. JClinMicrobiol. 2008;46(3):943-6.

37. Vives-Onos I, Codina-Grau MG, Noguera-Julian A, Blazquez-Gamero D, Fortuny C, Baquero-Artigao F, et al. Is polymerase chain reaction in neonatal dried blood spots reliable for the diagnosis of congenital Cytomegalovirus infection? Pediatr Infect Dis J. 2019;38(5):520-4. https://doi.org/10.1097/INF. 0000000000002144.

38. Kimberlin DW, Acosta EP, Sanchez PJ, Sood S, Agrawal V, Homans J, et al. Pharmacokinetic and pharmacodynamic assessment of oral valganciclovir in the treatment of symptomatic congenital cytomegalovirus disease. J Infect Dis. 2008;197(6):836-45. https://doi.org/10.1086/528376.

\section{Publisher's Note}

Springer Nature remains neutral with regard to jurisdictional claims in published maps and institutional affiliations.

Ready to submit your research? Choose BMC and benefit from:

- fast, convenient online submission

- thorough peer review by experienced researchers in your field

- rapid publication on acceptance

- support for research data, including large and complex data types

- gold Open Access which fosters wider collaboration and increased citations

- maximum visibility for your research: over $100 \mathrm{M}$ website views per year

At $\mathrm{BMC}$, research is always in progress.

Learn more biomedcentral.com/submissions 